\title{
ANALISIS FAKTOR SOSIODEMOGRAFI DALAM PENGAMBILAN KEPUTUSAN PEMILIHAN TEMPAT PERSALINAN DI KABUPATEN BANGKALAN
}

\author{
Uswatun Khasanah, Esyuananik, Anis Nurlaili \\ Kementerian Kesehatan Politeknik Kesehatan Surabaya Jurusan Kebidanan Bangkalan
}

\begin{abstract}
Parents Factors, Decisions, Selection Of Delivery Places. Maternal and Infant Mortality Rate in Indonesia remains high. Approximately $95 \%$ of maternal deaths occur during labor due to obstetric complications. Efforts are made by doing delivery in health facilities so it does not happen late referred and handled and can be anticipated if maternity in health facilities. Factors that are considered to influence the decision of maternity selection by maternity mothers are socio-demographic factors, namely education \& culture. High knowledge about health services causes individuals to tend to use health care facilities. This study aims to analyze the Sociodemografi Factors that Affect Decision Selection Place Birth to Maternity Mother. The research design using explanatory survey method with cross sectional design. This population are maternity mother in August-2016 with 51 samples of with multi stage sampling technique at coastal cluster, town and mountains, is Sepuluh health centers, Arosbaya health center and Galis health center. The data were taken by using quesioner and analized by Chi-Khuadrat. The results showed that the sociodemographic factor did not significantly influence the decision of maternity selection in maternal mother ( $p$ value) $0,05)$. It is recommended that midwives further improve counseling in pregnant women in the third trimester related to preparing for the delivery process, among others through.
\end{abstract}

Keywords : Parents Factors, Decisions, Selection Of Delivery Places

Abstrak: Faktor, Keputusan, Pemilihan Tempat Persalinan. Angka Kematian Ibu dan Angka Kematian Bayi di Indonesia masih tetap tinggi. Sekitar 95\% penyebab kematian ibu terjadi pada saat persalinan yang disebabkan oleh komplikasi obstetri. Upaya yang dilakukan dengan melakukan persalinan di fasilitas kesehatan sehingga tidak terjadi terlambat dirujuk dan ditangani serta dapat diantisipasi jika bersalin di fasilitas kesehatan. Faktor yang dianggap mempengaruhi keputusan pemilihan tempat persalinan oleh ibu bersalin antara lain faktor sosiodemografi yaitu pendidikan \& budaya. Pengetahuan yang tinggi tentang pelayanan kesehatan menyebabkan individu cenderung mengunakan fasilitas pelayanan kesehatan. Penelitian ini bertujuan untuk menganalisis Faktor Sosiodemografi Yang Mempengaruhi Keputusan Pemilihan Tempat Persalinan Pada Ibu Bersalin. Rancangan penelitian menggunakan metode survey eksplanatoris dengan desain cross sectional. Populasi ibu bersalin di wilayah Dinas Kesehatan Kabupaten Bangkalan pada bulan agustus-september 2016 dengan jumlah sampel 51 ibu bersalin dengan tehnik multi stage sampling pada puskesmas dengan cluster pantai, kota dan pegunungan, yakni puskesmas Sepuluh, puskesmas Arosbaya dan puskesmas Galis. Data diambil dengan menggunakan kuesioner dan 
diolah dengan uji statistik Chi-Khuadrat. Hasil penelitian menunjukkan bahwa faktor sosiodemografi tidak berpengaruh signifikan pada keputusan pemilihan tempat persalinan pada ibu bersalin $(p$ value $>0,05)$. Disarankan agar bidan lebih meningkatkan konseling pada ibu hamil trimester III terkait persiapan menjelang proses persalinan.

Kata Kunci: Faktor, Keputusan, Pemilihan Tempat Persalinan

\section{PENDAHULUAN}

Kematian ibu sebagian besar terjadi pada saat persalinan, dimana 9 dari 10 kematian ibu terjadi pada saat proses persalinan dan sekitarnya. (Depkes RI, 2009). Masih adanya wilayah desa yang melakukan persalinan di rumah yang ditolong oleh dukun, berdampak adanya komplikasi persalinan tidak dapat ditangani secara komprehensif (Shrestha, 2010). Beberapa faktor yang berkaitan dengan pengunaan fasilitas pelayanan kesehatan diantaranya akses pelayanan, usia, pendapatan keluarga, jarak fasilitas kesehatan, transportasi, pendidikan, pengetahuan, sikap, keadaan ibu dan bayi, Beberapa hasil penelitian terdahulu menyebutkan bahwa pendidikan yang tinggi dapat menyebabkan pengetahuan tentang kesehatan sehingga ibu cenderung memilih tempat persalinan di tenaga kesehatan (D'Ambruso, 2009). Pengetahuan yang tinggi tentang pelayanan kesehatan menyebabkan individu cenderung mengunakan fasilitas pelayanan kesehatan.

Pemilihan tempat bersalin dan penolong persalinan yang tidak tepat akan berdampak secara langsung pada kesehatan ibu. Setidaknya ada dua pilihan tempat bersalin yaitu di rumah ibu atau di unit pelayanan kesehatan (Rohmah, 2010). Tempat yang paling ideal untuk persalinan adalah fasilitas kesehatan dengan perlengkapan dan tenaga yang siap menolong sewaktu-waktu terjadi komplikasi persalinan. Minimal di fasilitas kesehatan seperti Puskesmas yang mampu memberikan Pelayanan Obstetrik dan Neonatal Emergensi Dasar (PONED). Persalinan di fasilitas kesehatan dengan perlengkapan dan tenaga yang siap menolong sewaktu - waktu terjadi komplikasi persalinan. Minimal di fasilitas kesehatan seperti puskesmas yang mampu memberikan pelayanan obstetrik dan neonatal emergensi dasar (PONED). Dipahami belum seluruh Puskesmas mampu untuk memberikan pelayanan dasar tersebut, minimal pada saat ibu melahirkan di Puskesmas terdapat tenaga yang dapat segera merujuk jika terjadi komplikasi (Kemenkes RI, 2010).

Berdasarkan hasil riset kesehatan dasar 2010, persalinan ibu anak terakhir dari kelahiran lima tahun terakhir menunjukkan bahwa $55.4 \%$ melahirkan di fasilitas kesehatan seperti rumah sakit (pemerintah dan swasta), rumah bersalin, Puskesmas, Pustu, praktek dokter atau praktek bidan. Terdapat 43,2\% melahirkan di rumah/ lainnya dan hanya 1,4 persen yang melahirkan di Polindes/Poskesdes. Di Kabupaten Bangkalan masih ditemukan persalinan di rumah pasien dengan penolong seorang bidan $\pm 10 \%$ (Dinkes Bangkalan, 2015).

Penelitian ini bertujuan Untuk mengetahui faktor sosiodemografi yaitu pendidikan dan budaya yang mempengaruhi keputusan pemilihan 
tempat persalinan pada ibu bersalin di Kabupaten Bangkalan.

Melalui penelitian ini diharapkan terpenuhi manfaat teoritis yaitu menambah wawasan dan pengetahuan tentang faktor sosiodemografi yang mempengaruhi pemilihan tempat persalinan di wilayah kabupaten Bangkalan.

\section{METODE PENELITIAN}

Rancangan

menggunakan metode survey eksplanatoris dengan desain cross sectional. Teknik sampling yang digunakan multi stage sampling pada Puskesmas dengan cluster pantai, kota dan pegunungan, yakni Puskesmas Sepuluh, puskesmas Arosbaya dan puskesmas Galis. Dalam penelitian ini digunakan sampel sebanyak 51 ibu bersalin. Data diambil dengan menggunakan kuesioner yang telah diuji validitas dan reliabilitas dan diolah dengan uji statistik ChiKhuadrat.

\section{HASIL PENELITIAN}

Tabel 1

Karakteristik Umum Responden

\begin{tabular}{lcc}
\hline \multicolumn{1}{c}{ Karakteristik } & n & \% \\
\hline Usia & & \\
$<20$ tahun & 4 & 7,8 \\
20-35 tahun & 45 & 88,2 \\
35 tahun & 2 & 3,9 \\
\hline Pekerjaan & & \\
IRT & 37 & 72,5 \\
PNS & 4 & 7,8 \\
Swasta & 10 & 19,6 \\
\hline Paritas & & \\
Primipara & 37 & 72,5 \\
Multipara & 12 & 23,5 \\
Grandemulti para & 2 & 3,9 \\
\hline Jenis Persalinan & & \\
SC & 3 & 5,9 \\
Normal & 48 & 94,1 \\
\hline
\end{tabular}

Berdasarkan tabel 1 dapat disimpulkan bahwa karakteristik umum responden terbanyak berusia 20-35 tahun $(88,2 \%)$, tidak bekerja/IRT $(72,5 \%)$, primipara $(72,5 \%)$ dan melahirkan secara normal $(94,1 \%)$

\section{Tabel 2}

Distribusi Frekuensi Variabel Bebas

\begin{tabular}{lcc}
\hline \multicolumn{1}{c}{ Variabel bebas } & n & \% \\
\hline Pendidikan & & \\
Dasar & 25 & 49 \\
Menengah & 18 & 35,3 \\
Tinggi & 8 & 15,7 \\
Budaya & & \\
Tidak mendukung & 20 & 39,2 \\
Mendukung & 31 & 60,8 \\
\hline
\end{tabular}

Berdasarkan tabel 2 didapatkan

data bahwa berdasarkan faktor sosiodemografi responden terbanyak memiliki tingkat pendidikan dasar $(45 \%)$ dengan budaya yang mendukung kearah pemilihan penggunaan fasilitas kesehatan

\section{Tabel 3}

Pengaruh Faktor Sosiodemografi

(Pendidikan Dan Budaya) Terhadap Keputusan Pemilihan Tempat Persalinan

\begin{tabular}{|c|c|c|c|c|}
\hline \multirow{3}{*}{ Variabel } & \multicolumn{3}{|c|}{$\begin{array}{l}\text { Keputusan pemilihan } \\
\text { tempat persalinan }\end{array}$} & \multirow{3}{*}{$\begin{array}{c}p \\
\text { value } \\
\text { (CI } \\
95)\end{array}$} \\
\hline & $\begin{array}{c}\text { Linnakes } \\
\text { Non } \\
\text { faskes } \\
\end{array}$ & \multicolumn{2}{|c|}{$\begin{array}{c}\text { Linnakes } \\
\text { Faskes }\end{array}$} & \\
\hline & $\mathrm{n} \quad \%$ & $\mathrm{n}$ & $\%$ & \\
\hline \multicolumn{5}{|l|}{ Pendidikan } \\
\hline 1. Dasar & 24 & 19 & 76 & \multirow{3}{*}{0,819} \\
\hline 2. Menengah & 16,7 & 15 & 83,3 & \\
\hline 3. Tinggi & 25 & 6 & 75 & \\
\hline \multicolumn{5}{|l|}{ Budaya } \\
\hline $\begin{array}{l}\text { 1. Tidak } \\
\text { mendukung }\end{array}$ & $5 \quad 25$ & 15 & 75 & \multirow[t]{2}{*}{0,897} \\
\hline 2. Mendukung & $6 \quad 19,4$ & 25 & 80,6 & \\
\hline $\begin{array}{l}\text { Berdas } \\
\text { tidak ada } \\
\text { sosiodemograf } \\
\text { budaya terha } \\
\text { tempat persali } \\
\text { sub variabel p }\end{array}$ & $\begin{array}{l}\text { rkan uji } \\
\text { pengaruh } \\
\text { baik pe } \\
\text { lap kepu }\end{array}$ & $\begin{array}{l}\text { al } \\
\text { did }\end{array}$ & $\begin{array}{l}\text { tistik } \\
\text { tara } \\
\text { kan } \\
\text { pe }\end{array}$ & $\begin{array}{l}\text { bahwa } \\
\text { faktor } \\
\text { naupun } \\
\text { milihan } \\
\text { ). Pada }\end{array}$ \\
\hline
\end{tabular}


dihitung karena jumlah sel $3 \times$ x 2 , sedangkan pada sub variabel budaya didapatkan bahwa budaya yang tidak mendukung memiliki resiko 1,39 kali lebih besar untuk terjadinya pemilihan tempat persalinan di non fasilitas kesehatan dibandingkan responden yang memiliki budaya yang mendukung.

\section{PEMBAHASAN}

Berdasarkan hasil uji satatistik didapatkan bahwa tidak ada pengaruh antara faktor sosiodemografi baik pendidikan maupun budaya terhadap keputusan pemilihan tempat persalinan $(p$ value $>0,05$ ).

Pendidikan adalah usaha sadar dan terencana untuk mewujudkan suasana belajar dan proses pembelajaran agar peseta didik secara aktif mengembangkan potensi dirinya untuk memiliki kekuatan spiritual keagamaan, pengendalian diri, kepribadian, kecerdasan, akhlak mulia, serta keterampilan yang diperlukan dirinya, masyarakat, bangsa dan Negara (UU RI, 2003). Perempuan dengan pendidikan menengah dan tinggi dibandingkan dengan pendidikan rendah, secara signifikan lebih memilih melahirkan di fasilitas kesehatan. Tingginya tingat pendidikan di masyarakat dapat menunjukkan kesadaran lebih besar akan pelayanan kesehatan dan kebutuhan akan kesehatan (Kruk, Et all, 2009).

Hasil penelitian menunjukkan sebagian besar responden berpendidikan dasar (49\%). Secara teori responden dengan tingkat pendidikan dasar memiliki kesadaran akan pelayanan kesehatan dan kebutuhan kesehatan lebih rendah dibandingkan tingkat pendidikan menengah dan tinggi. Namun tidak demikian pada hasil penelitian ini, dimana
$76 \%$ dari responden yang berpendidikan dasar justru memilih persalinan pada tenaga kesehatan di fasilitas kesehatan.

Berdasarkan sub variabel budaya didapatkan hasil bahwa responden dengan budaya yang tidak mendukung kearah kesehatan memiliki resiko 1, 39 kali lebih besar untuk terjadinya pemilihan tempat persalinan pada tenaga kesehatan di non fasilitas kesehatan dibandingkan responden yang memiliki budaya yang mendukung. Sistem nilai budaya yang sudah berpola merupakan gambaran sikap, pikiran, dan tingkah laku anggota/warga yang diwujudkan dalam bentuk sikap dan perbuatan dalam hidup masyarakat (Setiadi dkk, 2009; Koentjaraningrat, 2009; Mulyana dan Rakhmat, 2010). Keyakinan tradisional tentang melahirkan, dan rasa ketakutan pada lembaga medis menyebabkan seorang perempuan mempertahankan ketergantungan dan penolong persalinan (Mubarok, 2009). Masih belum sadarnya semua masyarakat yang siap melaksanakan perubahan perilaku, adanya pengaruh sosial budaya dengan bias gender dan masih kurangnya informasi serta kemampuan menerima dan menyerap suatu informasi akan mempengaruhi norma dan keyakinan masyarakat dalam memanfaatkan pelayanan kesehatan.

\section{KESIMPULAN DAN SARAN}

Dari hasil penelitian dan pembahasan, maka dapat ditarik kesimpulan bahwa tidak terdapat pengaruh faktor sosiodemografi yaitu pendidikan dan budaya terhadap keputusan pemilihan tempat persalinan

1. Saran ilmiah

Perlu dilakukan penelitian lebih lanjut mengenai faktor-faktor lain yang berpengaruh terhadap keputusan 
pemilihan tempat persalinan misalnya kualitas tempat persalinan.

1. Saran praktis

\section{Dinas kesehatan}

Perlu dilakukan evaluasi terhadap fasilitas kesehatan yang terdapat di desa (Polindes, Poskesdes) dan fasilitas kesehatan pribadi (BPM) untuk meningkatkan kualitas dan kuantitas pelayanan terhadap masyarakat khusunya ibu dan anak.

2. Tenaga kesehatan (bidan)

a. Bidan agar lebih meningkatkan konseling pada ibu hamil trimester III terkait persiapan menjelang proses persalinan antara lain melalui program P4K termasuk persiapan transportasi untuk ibu bersalin.

b. Bidan bekerjasama dengan tokoh masyarakat untuk lebih memfungsikan rumah tunggu kelahiran sehingga keterlambatan dalam penanganan persalinan dapat dicegah.

\section{DAFTAR RUJUKAN}

Depkes RI. 2009. Kompetensi Bidan Indonesia. Jakarta.

Depkes, RI, 2010. Laporan Nasional Riset Kesehatan dasar. Jakarta.

Kemenkes RI, 2010. Pedoman Pelaksanaan Pelayanan Kesehatan Ibu di Fasilitas Kesehatan. Dirjen Bina Kesehatan Masyarakat. Jakarta.

Kepmenkes RI. 2011. Petunjuk Teknis Jaminan Persalinan. Jakarta.

Koentjaraningrat. 2009. Ilmu Antropologi. Rineka Cipta. Jakarta.

Kruk, M. E., Mbaruku, G., McCord, C. W., Moran, M., Rockers, P. C. \&
Galea, S, 2009, Bypassing primary care facilities for childbirth: a population-based study in Rural Tanzania. Health Policy Plan, 24(4): 279-88

Mubarok WI. 2009. Sosiologi Untuk Keperawatan. Salemba Medika. Jakarta.

Setiadi EM, Hakam KA, Effendi R. 2009. Ilmu Sosial dan Budaya Dasar. Kencana. Jakarta.

Shrestha, 2010. The village midwife program and infant mortality in Indonesia Bulletin of Indonesian Economic Studies, 46(2): 193-211

UU RI. 2003. UU RI no.20 Tentang Sistem Pendidikan Nasional. Jakarta.

Winardi J. 2008. Motivasi Pemotivasian dalam Manajemen. Rajawali Press. Jakarta. 